\title{
Remodeling science education
}

\author{
David Hestenes \\ Department of Physics, Arizona State University, Tempe, Arizona 85282, USA \\ For correspondence: hestenes@asu.edu
}

\begin{abstract}
Radical reform in science and mathematics education is needed to prepare citizens for challenges of the emerging knowledge-based global economy. We consider definite proposals to establish: (1) Standards of science and math literacy for all students. (2) Integration of the science curriculum with structure of matter, energy, models and modeling as unifying themes. (3) Pedagogy promoting scientific inquiry and argumentation. (4) Sustained professional development and support for teachers. (5) Institutional support from local universities for continuous upgrades in curriculum and teaching practices. Physics plays a central role in all these reforms.
\end{abstract}

\section{Introduction}

Rapid emergence of a global economy driven by science and technology has precipitated a crisis in the education systems of all nations. Radical education reform is needed to produce (1) science literate citizens and consumers, provide (2) workplace readiness (the technical foundation for an effective workforce), and maintain (3) a technology pipeline (educating scientists and engineers to sustain economic growth). However, the problems of systemic education reform are complex and must be understood before effective action can be taken. That understanding is what we seek here.

STEM Education has recently become a code word for the education crisis in the U.S. The acronym STEM for Science, Technology, Engineering and Mathematics was created within the National Science Foundation (NSF) as policy makers struggled to coordinate funding for comprehensive education reform. Unfortunately, planning and policy has lagged far behind the invention of acronyms. My purpose here is to describe the design and implementation of effective STEM education reform derived from decades of physics education R\&D in the United States. Most of its components have been successfully tested, but full implementation still awaits adequate funding. Even so, I hope you find elements of the plan convincing and adaptable to STEM education in your own country.

Though problems of STEM education exist at all grades levels, they are most critical in the middle grades of the K-12 system, because that is where the personal orientation toward science and technology for most students is set for life. Accordingly, the first problem of STEM education is to establish standards for science and math literacy for all students; thus to provide them with functional knowledge and skills for active participation in society. Happily, appropriate literacy standards are already available, so the problem reduces to implementation and assessment to assure that the standards are met.

The STEM acronym reflects belated recognition of breakdown in the rigid separation of traditional academic disciplines driven by accelerating advances in science and engineering. Accordingly, the second problem of STEM education is to remodel the science and math curriculum in accordance with current science and technology. If students are to grasp the significance of advances in molecular biology and nanotechnology by grade 12, the traditional biology, chemistry, physics course sequence must be reversed. Physics must come first to introduce students to quantitative methods along with 
concepts of energy and the atomic-molecular structure of matter that run through the entire curriculum. Throughout the curriculum students must be engaged in scientific inquiry and explanation so they learn how to form and justify rational opinions on their own.

Ultimately, all reform takes place in the classroom, so the teacher is the critical component in implementation. Accordingly, the third problem of STEM education is developing and maintaining teacher expertise in science content and pedagogy. This is where educational systems fail most miserably. For development of genuine expertise requires continuous effort over a decade or more with stimulation from a professional community of peers.

This brings up the ultimate problem in educational reform: Establishing institutional mechanisms to promote high-quality educational change. Teachers and their schools lack the necessary expertise in science and technology as well as the institutional resources to keep up-to-date with advances in science content, curriculum materials and pedagogy. Those resources reside primarily in universities, especially in the math, science and engineering faculties. As an ENGINE to drive rapid, continuous and comprehensive K-12 STEM education reform in its region, each public university is advised to establish an Institute for sustained professional development and support of local STEM teachers.

\section{Science and math literacy in curriculum and assessment}

To set baseline goals for STEM curriculum design and assessment, developers are well advised to follow the internationally recognized PISA framework for science and mathematics literacy (2006).

In a landmark publication, Science for All Americans (Rutherford and Almgren, 1990), AAAS Project 2061 defined scientific literacy as the central goal of public STEM education. This was followed by a more detailed framework in Benchmarks for Scientific Literacy (AAAS 1993). Now, nearly two decades later, it is hard to detect a trace of this framework in the textbook-driven public education or the policies of the U.S. Department of Education.

Fortunately, the goals of scientific and mathematical literacy have been taken up with renewed vigor at the international level in creation of the Programme for International Student Assessment (PISA) by the Organisation for Economic Cooperation and Development (OECD). To date, PISA has assessed well over a million students in 60 countries. The 30 member nations of the OECD along with 27 partner nations that participated in the most recent testing cycle account for roughly $90 \%$ of the world economy.

PISA assessment is directed at students of age 15, because that is near the end of compulsory schooling in most OECD states. The goal is to assess student progress in acquiring and applying the skills and knowledge necessary to participate fully in the society of today. Analysis of the extensive results is available on the Web. Two of the most significant conclusions are: First, results of the highest performing nation, Finland, can in large part be attributed to its greater equity in educational opportunity. Second, in the best performing countries teachers are regarded as professionals; revered by society, the teaching profession is competitive, and governments in these countries ensure that the best and the brightest enter the profession through subsidies and intensive teacher training programs.

The point of greatest interest here is that design of the PISA assessment instruments is guided by a well-crafted PISA Framework for Scientific, Reading and Mathematical Literacy (Cresswell and Vassayettes, 2006) developed by outstanding international teams of domain experts. This framework is simpler and more practical than the Benchmarks, though it captures all the essential aspects of science and math literacy, and it has the great advantage of intimate ties to an internationally credible education assessment program. Accordingly, it can be recommended as a core component of a middle school curriculum framework and professional development program. PISA test questions are freely 
available to evaluate middle school programs, and the large PISA data base can be used to assess the significance of results.

The AAAS Benchmarks will remain a valuable resource for curriculum design, but we are mindful that it has a serious weakness (Thompson, 1994). In extolling the virtues of mathematical abstraction and rigor, Benchmarks has inadvertently promoted the unhealthy separation between math and science that exists in our schools today. In consequence, most math teachers have only the vaguest concept of science literacy and its intimate connection with math literacy. This flaw is corrected in the PISA literacy framework.

PISA as a framework for instructional design: "What is it important for citizens to know, value, and be able to do in situations involving science and technology?" (Cresswell et al, 2006, p. 20) This is the question that guided PISA scientific literacy framework writers. The competencies that they outline call upon students to demonstrate both cognitive and affective aspects of scientific literacy - the focus of the 2006 PISA assessment. The guiding principle in the development of the mathematical literacy framework is a need for the "capacity to identify and understand the role that mathematics plays in the world, to make well-founded judgments and to use and engage with mathematics in ways that meet the needs of that individual's life as a constructive, concerned and reflective citizen." (p. 72) The upshot for curriculum design is that the PISA math-science assessment items are situated in real world contexts.

Of particular note is the PISA emphasis on modeling as a means of framing both science and mathematics thinking and learning. That is illustrated by many excellent examples. Both mathematics and science items begin with problems that are situated in reality. To solve these problems the student must abstract relevant contextual information and arrange it into a conceptual structure (a model) that can then be manipulated to find answers to a series of questions. As seen below, this closely parallels the design tenets of modeling instruction for both mathematics and science. The PISA scientific and mathematical literacy frameworks provide an excellent source for development of transdisciplinary mathematics and science modeling materials for middle school students.

\section{Quantitative models: the core of scientific knowledge}

A thorough analysis of the introductory physics course (Hestenes, 1997) reveals that a handful of basic mathematical models provides the essential structure for the entire subject. Here is the list along with a few hints of applications.

Basic Mathematical Models:

1. Constant rate (linear change): graphs and equations for straight lines (proportional reasoning, constant velocity, acceleration, force, momentum, energy, etc.)

2. Constant change in rate (quadratic change) graphs and equations for parabolas (constant acceleration, kinetic and elastic potential energy, etc.)

3. Rate proportional to amount: doubling time, graphs and equations of exponential growth and decay (monetary interest, population growth, radioactive decay, etc.)

4. Change in rate proportional to amount: graphs and equations of trigonometric functions (waves and vibrations, harmonic oscillators, etc.)

5. Sudden change: stepwise graphs and inflection points (Impulsive force, etc.)

These models characterize basic quantitative structures that are ubiquitous not only in physics but throughout the rest of science. Their applications to science and modern life are rich and unlimited. Accordingly, skill in using these models in a variety of situations is an essential component of math and science literacy. That skill should be cultivated deliberately and systematically with repeated activities throughout the STEM curriculum. 
Integration of mathematics with physics should be strongly emphasized in the middle grades 7 through 9, and implicit throughout the curriculum. In modeling instruction, abstract mathematical concepts such as variable, function and rate can be explored within the context of mathematical models with concrete applications in physics and deployed to other subjects (i.e. chemistry, biology, economics).

By direct experience, students learn there is much more to a scientific model than the abstract structure of a mathematical model. In a scientific model variables must be related to observable experience and quantified with measurement procedures. Here they see another role for mathematics: statistical concepts such as mean, standard deviation, and error analysis are applied in the process of matching models to data collected by students using calculators, computer interfaces and measurement probes. Technology facilitates measurement and data-gathering, thus shifting the focus to data interpretation, model identification and analysis.

The ideal modeling curriculum begins in middle school with an emphasis on proportional reasoning as a first step in developing the concepts of function and graphs in modeling motion and money transactions. This is an ideal prelude to the central mathematical theme of quantitative reasoning with models. Quantitative reasoning with number and unit goes hand-in-hand with modeling and measurement, which couples the mathematics to the science (Lesh \& Doerr, 2003a,b). A middle school workshop for teachers fleshes this out with a hands-on introduction to basic physical variables, including time, position, velocity, mass, density, temperature and energy. Proportional reasoning is an essential component of quantitative reasoning, so evaluation should be designed to compare results of instruction in both.

\section{Modeling instruction as instruction in modeling}

The name Modeling Instruction refers to making and using conceptual models of real systems and processes (both natural and artificial) as central to learning and doing science and engineering. Though adoption of "models and modeling" as a unifying theme for science and mathematics education has been strongly recommended by NSES (1996). NCTM (2000) and AAAS Project 2061 (1993), no other program has implemented that theme so thoroughly as the Modeling Instruction Project for physics (See website), which is pioneering its extension to the entire STEM curriculum.

Modeling Instruction has much in common with Realistic Mathematics Education (RME), a teaching and learning theory in mathematics education developed by the Freudenthal Institute in the Netherlands (Freudenthal, 1991, 1993).

Modeling Instruction integrates a research-based, student-centered teaching methodology with a model-centered curriculum. It applies structured inquiry techniques developed in the Modeling Instruction Project to teaching basic skills in mathematical modeling, proportional reasoning, quantitative estimation, and data analysis. This contributes to development of critical thinking and communication skills, including the ability to formulate well-defined opinions and evaluate or defend them with rational argument and evidence. As found in the case of physics, extension of Modeling Instruction more broadly can be expected to produce significant improvement in student scores on standardized reading, writing and mathematics tests as well as in higher-order thinking.

A synopsis of the Modeling Method of Instruction is given in Box 1. Here are a few words to highlight unique features most responsible for its success. Its big difference from other approaches is that all stages of inquiry are structured by modeling principles. Typical inquiry activities (or investigations) are organized into modeling cycles about two weeks long (Wells et al, 1995). The teacher subtly guides students through the activities with modeling discourse (Hestenes 1997), which means that 
the teacher promotes framing all classroom discourse in terms of models and modeling. The aim is to sensitize students to the structure of scientific knowledge, in both declarative and procedural aspects. Its effectiveness is well established (Desbien 2002, Megowan 2007).

The culmination of student modeling activities is reporting and discussing outcomes in a whiteboard session (Wells 1995, Hestenes 1997). This may be where the deepest student learning takes place, because it stimulates assessing and consolidating the whole experience in recent modeling activities.

Whiteboard sessions have become a signature feature of the Modeling Method, because they are flexible and easy to implement, and so effective in supporting rich classroom interactions. Each student team summarizes its model and evidence on a small $(2 \mathrm{ft} \times 2.5 \mathrm{ft})$ whiteboard that is easily displayed to the entire class. This serves as a focus for the team's report and ensuing discussion. Comparison of whiteboards from different teams is often productively provocative. The main point is that class discussion is centered on visible symbolic student-generated inscriptions that serve as an anchor for shared understanding.

\section{Box 1: Synopsis of the MODELING METHOD}

The Modeling Method aims to correct many weaknesses of the traditional lecturedemonstration method, including the fragmentation of knowledge, student passivity, and the persistence of naive beliefs about the physical world.

\section{Coherent Instructional Objectives}

- To engage students in understanding the physical world by constructing and using scientific models to describe, to explain, to predict and to control physical phenomena.

- To provide students with basic conceptual tools for modeling real objects and processes, especially mathematical, graphical and diagrammatic representations.

- To familiarize students with a small set of basic models as the content core of science.

- To develop insight into the structure of scientific knowledge by examining how models fit into theories.

- To show how scientific knowledge is validated by engaging students in evaluating scientific models through comparison with empirical data.

- To develop skill in all aspects of modeling as the procedural core of scientific knowledge.

\section{Student-Centered Instructional Design}

- Instruction is organized into modeling cycles which move students through all phases of model development, evaluation and application in concrete situations - thus promoting an integrated understanding of modeling processes and acquisition of coordinated modeling skills.

- The teacher sets the stage for student activities, typically with a demonstration and class discussion to establish common understanding of a question to be asked of nature. Then, in small groups, students collaborate in planning and conducting experiments to answer or clarify the question.

- Students are required to present and justify their conclusions in oral and/or written form, including a formulation of models for the phenomena in question and evaluation of the models by comparison with data.

- Technical terms and concepts are introduced by the teacher only as they are needed to sharpen models, facilitate modeling activities and improve the quality of discourse.

- The teacher is prepared with a definite agenda for student progress and guides student inquiry and discuss5ion in that direction with questions and remarks.

- The teacher is equipped with a taxonomy of typical student misconceptions to be addressed as students are induced to articulate, analyze and justify their personal beliefs.

Primacy of modeling over problem solving. In Modeling Instruction, problem solving is addressed as a special case of modeling and model-based reasoning. Students are taught that the solution to a problem follows directly from a model of the problem situation. The modeling cycle applies equally 
well to solving artificial textbook problems and significant real world problems of great complexity. This approach is readily transferred to mathematics teaching, as math teachers who attend modeling workshops have learned!

The modeling method, with its emphasis on coherence and self-consistency of the model, is especially-well-suited to detection and correction of ill-posed problems, where the given information is either defective or insufficient. Moreover, students are thrilled when they realize that a single model generates solutions to an unlimited number of problems. A number of studies find that modelcentered instruction promotes expert problem solving behavior in students (Malone, 2006, 2008).

\section{Middle school physical science and mathematics}

Conceptual underpinnings for physics and chemistry that are important components of scientific literacy even for students who do not continue with the recommended sequence of more advanced courses should be addressed in a middle school Physical Science course. A workshop to prepare for teaching such a course is available in the MNS graduate program (PHS 534 in Box 2). The course is designed for grade 8 , but can easily be spread out over grades 7 and 8 . The course is intended for integration with middle school mathematics so both science and math teachers are encouraged to attend the workshop, especially in teams from the same school.

The course emphasizes proportional reasoning as a starting point for developing the concept of function and in relationship to graphing and modeling motion and money contexts. This is an ideal prelude to the central mathematical theme of quantitative reasoning with models. Quantitative reasoning with number and unit goes hand-in-hand with modeling and measurement, which couples the mathematics to the science (Lesh \& Doerr, 2003a,b).

The workshop fleshes this out with a hands-on introduction to basic physical variables, including time, position, velocity, mass, density, temperature and energy. All essential concepts are introduced and developed through specific activities that are ready for immediate use with students.

We have space here only for an outline of topics addressed in the physical science course:

1. Modeling geometric properties of matter: size, shape and place.

a. Measurement of length (rulers, units, congruence, accuracy)

b. Measurement of area (dimension, size, shape and symmetry)

c. Measurement of volume (units, irregular shapes, graphical relations of dimensions)

d. Maps as models of place, size and shape (position vs. distance, scaling)

2. Physical properties of matter

a. How much stuff? mass (measurement by balancing, conservation under change)

b. Kinds of stuff: density (material kinds and states; smallest parts)

c. Systems: boundaries and environments (open and closed, matter exchange)

3. Models of motion and interaction (mathematics of change, proportional reasoning)

a. Particle models (displacement and motion maps)

b. Measurement of time (clocks; position-time graphs: slope as velocity)

c. Constant and variable velocity (measurement with motion sensors, acceleration)

d. Kinetic energy (energy conservation and transfer in collisions)

4. Agents and interactions

a. Forces (long and short range; gravitational, electric, magnetic)

b. Interaction (potential) energy to hold bodies together

c. Energy \& change (change of state; thermal and chemical processes)

d. Newton's Laws 


\section{Energy thread for physics first.}

Although energy is a conceptual thread running through the entire science curriculum, it should be addressed most intensively in the ninth grade physics course focused on Energy and Structure of Matter.

A workshop on teaching such a course will be attractive to both physics and chemistry teachers at any level, whether or not they are interested in broader curriculum reform. Some course topics could be included in either physics or chemistry courses, so the importance of integrating those courses is obvious. The workshop is also recommended for teachers of ninth grade math, as they will include explicit designs for coordinating (if not integrating) math with physics.

Design of the energy thread should be guided by the need to teach physics as a foundation for chemistry. In particular, the usual Newtonian emphasis on force and motion should be reduced (but not omitted) in favor of internal energy and energy transfer, which play much greater roles in chemistry. The course design should incorporate innovations from physics education research over the last two decades. For example, the general energy conservation law (First Law of Thermodynamics) can be introduced from the beginning by modeling particles with internal energy. This decouples energy and momentum laws (which are inextricably linked in Newtonian mechanics). Among other things, it greatly facilitates the treatment of thermodynamics and the transition by analogical reasoning from macroscopic to microscopic (atomic and molecular) models of matter. Indeed, the ubiquitous role of energy conservation has led Alonso and Finn (1995) to coin the phrase "The Equation of Everything" for the First Law of Thermodynamics. This figurative expression nonetheless captures students' imagination and is a bit less imposing than the "First Law of Thermodynamics." By the way, this approach also corrects serious conceptual mistakes in energy arguments that are common in college as well as high school textbooks (Sherwood 1983, Arons 1987).

Energy storage and transfer serves as a unifying theme that binds the various topics into a coherent conceptual system. The emphasis should be on qualitative reasoning with models and diagrammatic tools such as energy bar charts, pie charts and flow diagrams to establish a solid foundation for energy arguments throughout the high school science curriculum, as well as for quantitative reasoning that follows.

In fashioning the energy strand, strong emphasis should be placed on potential energy diagrams as well as the concept of potential. Physics education research shows that exposure to and practice with the idea of potential in a mechanical context significantly improves subsequent student learning and understanding of electrical potential (Brewe, 2003). As students move on to chemistry, a solid understanding of electrical potential and potential energy changes will provide the foundation on which conceptual understanding of bonding and electrochemical phenomena can be built.

Finally, the physics course should develop at length the concept of electrical potential to explain binding of atoms and molecules as well as interaction of matter with light. But that is a well-known story so it need not be elaborated here.

\section{Remodeling chemistry}

Sad to say, the standard high school chemistry course begins with a whirlwind tour of internal structure of the atom, without providing either a rationale for the need to know this structure, or more than a cursory treatment of the evidence used to support the current view. As a result, the chemistry course relies heavily on rote learning, because the atomic theory needed for conceptual understanding requires a physics course. A physics course before chemistry is helpful but not sufficient to solve this problem. It is equally important to clarify the structure of chemistry by 
defining the models needed to explain particular chemical properties. Only from well-defined models can precise inferences be made. Models that explain structure of the periodic table of the elements and mechanisms for chemical change are of central importance. Pedagogically acceptable models will appeal to empirical evidence for a progressively more refined model of matter without resorting to quantum mechanical explanations that students are not prepared to understand. For example, empirical evidence is sufficient to infer the existence of quantized energy levels, so a model of the atom that accounts for the interaction of light and electrons can be developed without quantum mechanical justification. At the same time, a modeling chemistry course cultivates math literacy by stressing proportional reasoning over rote use of algorithms to solve a wide variety of problems (stoichiometry and gas laws).

\section{A modeling model of professional development.}

As forcefully argued in a landmark report by the National Research Council (1999), significant STEM education reform requires curriculum coordination across all grades. It cannot be achieved piecemeal, one course at a time.

Reforms of the K-12 STEM curriculum discussed above are as radical as they are necessary! Consequently, they cannot be achieved without intensive training and sustained support for inservice teachers. A model for this kind of professional development has been created and thoroughly tested by the Modeling Instruction Project (See website). It has been institutionalized at Arizona State University as an integrated system of summer courses in a graduate program for inservice teachers (Box 2).

One of the most important lessons learned in the Modeling Instruction Project is that the studentcentered, inquiry-oriented modeling pedagogy (Box1) cannot be transmitted through a book, even to teachers. It is a complex system of social practices that can be learned only from direct interaction with other teachers coupled to classroom practice with students. Even talented teachers cannot make fully effective use of Modeling curriculum materials without being introduced to them in a workshop of three weeks or more. Consequently, Modeling curriculum modules are distributed only in connection with workshops, though they are freely available for inspection on the Web by parties who are interested enough to ask for the password.

Ideally, universities should partner with local schools and school districts to organize STEM teachers into learning communities that support continued professional development for successful implementation of the new curriculum. Teachers should be introduced to the curriculum in workshops that promote collaboration in teams as they practice teaching it. Collaboration continues through the school year when, under leadership of a teacher who is proficient in modeling pedagogy, they meet regularly to resolve problems and discuss improvements in their implementation with students. This process can be continued to sustain reforms against inevitable teacher turnover. Induction of new teachers begins with the summer workshop that introduces them to the curriculum and continues in the supportive learning community with guidance from an experienced mentor. Indeed, it would be surprising if this arrangement does not improve job satisfaction and thereby reduce teacher turnover significantly

This ideal has yet to be fully implemented even in Arizona, owing to the profound inertia of school and university administrations. 


\section{Box 2: ASU Catalog description of the MNS program $<$ http://modeling.asu.edu/MNS/MNS.html>}

Master of Natural Science (MNS) in Physics for inservice teachers

- Eligibility. The program is open to inservice high school teachers who have completed college-level physics and one semester of introductory calculus. Underprepared teachers can make up deficiencies in regularly scheduled courses.

- Requirements. A total of 30 graduate credits is required, selected from the Courses in physics and physical science for teachers listed below. A minimum of 15 credits must be taken in the "Teaching Methods" and "Integrated Science" categories listed there. This must include

- Six credits in "Methods of Physics Teaching," unless courses with an equivalent emphasis on physics pedagogy have been taken as an undergraduate.

- An Action Research Project for two or three credits.

- A minimum of six credits must be taken in the "Contemporary Physics" category. Graduate courses in physics or other natural sciences can apply toward the remaining credits if approved by the student's supervisory committee.

\section{Master of Natural Science in Physics with High School Certification}

This option is open to graduate students with a BS/BA in physics or a comparable background in engineering. Requirements are the same as for the inservice option, except that the following must be included for certification:

- EDP 510 Essentials of Classroom Learning, 3 credits from College of Education.

- RDG 507 Content Area Literacy, 3 credits from the College of Education.

- PHS 584 Student Teaching in High School, 8 credits to cover the state-mandated 8 weeks of high school teaching.

Including these 14 credits, a total of 36 credits is required for the degree with certification.

\section{Courses in physics and physical science for teachers}

Category I: Teaching Methods

PHS 530: Methods of Physics Teaching I (3)

PHS 531: Methods of Physics Teaching II (3)

PHS 534: Methods of teaching physical science (3)

PHS 593: Action Research in Physical Science (1-3)

PHS 598: Leadership Workshop (1)

\section{Category II: Integrated Science}

PHS 505: Energy and the Environment (3)

PHS 540: Integrated Physics and Chemistry (3)

PHS 542: Integrated Mathematics and Physics (3)

PHS 550: Physics and Astronomy (3)

PHS 556: Astrophysics (3)

CHM 594: Modeling Instruction in High School Chemistry I \& II (3. 3)

\section{Category III: Contemporary Physics}

PHS 560: Matter and Light (3)

PHS 564: Light and Electron Optics (3)

PHS 581: Structure of Matter and its Properties (3)

PHS 570: Spacetime Physics (3)

PHS 593: Advanced Projects in Physical Science (1-4)

\section{References}

Arons, A. (1997). Teaching Introductory Physics, New York: Wiley.

Alonzo, M., and Finn, E., An Integrated Approach to Thermodynamics in the Introductory Physics Course, The Physics Teacher. 33: 297-310 (1995).

American Association for the Advancement of Science (1993), Project 2061 Benchmarks Online. http://www.project2061.org/tools/bench/bo/frame.html.

Brewe, E. (2003), Energy Thread in Introductory Physics, PhD. Thesis, ASU. http://modeling.asu.edu/R\&E/Research.html

Cresswell J. \& Vassayettes, S. (2006). Assessing Scientific, Reading and Mathematical Literacy: A Framework for PISA 2006. Paris, France: Organization for Economic Cooperation and Development. http://www.oecd.org/

Desbien, D. (2002). Modeling discourse management compared to other classroom management styles in university physics. Unpublished Doctoral dissertation, Arizona State University, Tempe, Arizona. http://modeling.asu.edu/R\&E/Research.html.

Freudenthal, H. (1991). Revisiting Mathematics Education. China Lectures. Dordrecht: Kluwer Academic Publishers.

Freudenthal, H. (1993). Thoughts on Teaching Mechanics, Didactical Phenomenology of the Concept of Force. Educational Studies in Mathematics 25, 71-87. 
Hestenes, D. (1997). Modeling Methodology for Physics Teachers. In E. Redish and J. Rigden (Eds.), The changing role of the physics department in modern universities. Part II (pp. 935-957). American Institute of Physics. http://modeling.asu.edu/R\&E/Research.html.

Hestenes, D. (2008) Notes for a Modeling Theory of Science Cognition and Physics Education. In E. van den Berg, A. Ellermeijer \& O. Slooten (eds.) Modelling in Physics and Physics Education. U. Amsterdam. http://modeling.asu.edu/R\&E/Research.html.

Lesh, R. and Doerr, H. M. (2003a). Beyond Constructivism, Mathematical Thinking and Learning, 5(2\&3), 211-233.

Lesh, R, and Doerr, H. (eds) (2003b). Beyond Constructivism: Models and modeling perspectives on mathematics problem solving, learning, and teaching. New Jersey: Lawrence Erlbaum Associates.

Malone, K. (2006). A Comparative Study of the Differences between Modeling and Non-Modeling High School Physics Students Cognitive and Metacognitive. Unpublished Doctoral dissertation, Carnegie Mellon University, Pittsburgh, PA. http://modeling.asu.edu/R\&E/Research.html.

Malone, K. (2008), Correlation between knowledge structures, force concept inventory, and problem-solving behaviors. Physical Review Special Topics-- Physics Education Research 4, 020107.

Megowan, C. (2007). Framing Discourse for Optimal Learning in Science and Mathematics. Unpublished Doctoral dissertation, Arizona State University, Tempe, Arizona. http://modeling.asu.edu/R\&E/Research.html.

Modeling Instruction Project: http://modeling.asu.edu.

National Council of Teachers of Mathematics (2000). Principles and Standards for School Mathematics, Reston, VA. http://standards.nctm.org.

National Research Council (1996), National Science Education Standards, National Academy Press, Wash. DC.

National Research Council (1999), Designing Mathematics of Science Curriculum Programs, a Guide for Using Mathematics and Science Education Standards, National Academy Press, Wash. DC.

PISA (2007). The Programme for International Student Assessment. http://www.oecd.org/dataoecd/51/27/37474503.pdf

Rutherford, F.J. and Ahlgren, A. (1990). Science for All Americans. New York: Oxford.

Sherwood, B. (1983). Pseudowork and Real Work, American Journal of Physics 51: 597.

Thompson, P. (1994), Bridges between Mathematics and Science Education, Project 2061 Conference on Developing a Research Blueprint. http//pat-thompson.net/PDFversions/1994Bridges.pdf.

Wells, M., Hestenes, D., and Swackhamer, G. (1995). A Modeling Method for High School Physics Instruction, American Journal of Physics 63, 606-619. http://modeling.asu.edu/R\&E/Research.html. 